\title{
Eye Movements and Processing Stages in Reading: Relative Contribution of Visual, Lexical, and Contextual Factors
}

\author{
Manuel G. Calvo and Enrique Meseguer \\ University of La Laguna
}

\begin{abstract}
The independent and the combined influence of word length, word frequency, and contextual predictability on eye movements in reading was examined across processing stages under two priming-context conditions. Length, frequency, and predictability were used as predictors in multiple regression analyses, with parafoveal, early, late, and spillover cye movement measures as the dependent variables. There were specific effects of: (a) length, both on where to look (how likely a word was fixated and in which location) and how long to fixate across all processing stages; (b) frequency, on how long to fixate a word, but not on where to look, at an early processing stage; and (c) predictability, both on how likely a word was fixated and for how long, in late processing stages. The source of influence for predictability was related to global rather than to local contextual priming. The contribution of word length was independent of contextual source. These results are relevant to determitie both the time course of the influence of visuat, lexical, and contextual factors on eye movements in reading, and which main component of eye movements, that is, location or duration, is affected.

Key words: length, frequency, predictubility, context, eye movements, time course, reading
\end{abstract}

\begin{abstract}
El estudio investiga la influencia especifica y la conjunta que la longitud de las palabras, su frecuencia léxica y su predecibilidad contextual tienen sobre los movimientos oculares durante la lectura, a lo largo de varios estadios de procesamiento y en dos condiciones contextuales. Longitud, frecuencia y predecibilidad fueron predictores en un análisis de regresión múltiple, mientras que medidas parafoveales, tempranas, tardias y de arrastre en los movimientos oculares fueron las variables dependientes. Se encontraron efectos específicos de: (a) la longitud, sobre dónde se fija la mirada y durante cuánto tiempo, en todas las fases de procesamiento; (b) la frecuencia léxica, sobre cuánto tiempo dura la fijación, pero no dónde se produce ésta, en una fase temprana de procesamiento; y (c) la predecibilidad, sobre la probabilidad y duración de la fijación, en una fase tardía de procesamiento. La fuente de influencia de la predecibilidad fue global más que local. La contribución de la longitud fue independiente del contexto. Estos resultados son relevantes para determinar el curso temporal de la influencia de factores visuales, léxicos y contextuales sobres los movimientos oculares en la lectura, y qué componente-ubicación y/o duración-es afectado.

Palabras clave: longitud, frecuencia léxica, predecibilidad, contexto, movimientos oculares, curso temporal, lectura
\end{abstract}

This rescarch was supported by Grant BSO2001-3753 from the DGI, Spanish Ministry of Science and Technology. We are grateful to Keith Rayner, Alan Kennedy, and Jukka Hyönä for their belpful comments on an earlier version of this article.

Correspondence concerning this article should be addressed to Manuel G. Calvo. Departamento de Psicología Cognitiva. Universidad de La Laguma. 38205 La Laguna. Sta. Cruz de Tenerife. Spain. Fax: 0034922317461 . E-mail: mgcalvo@ull.es 
The aim of this study is (a) to quantify the specific influence of word length, wotd frequency, and contextual predictability on eye-fixation location and duration during reading, after the contribution of each of the other two factors is partialled out; (b) to examine their temporal locus of influence, that is, whether the contribution of these factors varies across processing stages during reading; and (c) to determine the source of contextual influence and whether the effects of length and lexical frequency vary as a function of changes in the source of context constraints. This will indicate the relative involvement of these factors in the where (i.e., whether and in which location a word is fixated) and the when (i.e., how long a word is fixated) mechanisms governing eye movements in reading (see Hyönä \& Pollatsek, 2000; Rayner, 1998).

Regarding our first aim, we will quantify the relative contribution of length, frequency, and predictability by means of simultaneously including them as predictors in a multiple regression analysis, with eye movement measures as the dependent variables. The $s r^{2}$ statistic will determine the unique variance in eye movements explained by each factor, whereas the $R^{2}$ statistic will reveal the combined variance due to all three (Tabachnick \& Fidell, 1989). Secondly, we will examine the time course of influence of the factors at issue by using eye movement measures related to parafoveal, early, late, and spillover processing when reading a target word and the regions preceding and following it within a sentence. Lastly, we will explore the nature of contextual influence and its possible interaction with length and frequency by means of presenting the same target words in two different contexts: One assumed to induce both associative word-based priming and high-level integrative inferences and the other inducing only associative priming on the target word.

Word length (in number of characters) has been shown to affect several eye movement measures related to fixation location and also to fixation duration. Thus, regarding location, increases in word length are related to increments in the probability of fixating a word (e.g., Rayner \& McConkie, 1976; Rayner, Sereno, \& Raney, 1996), the landing position (i.e., further into the word; e.g., McConkie, Kerr, Reddix, \& Zola, 1988; Rayner, 1979), the number of fixations before first leaving the word (e.g., Hyonna \& Olson, 1995), the length of saccades to and/or from the target word (e.g., Kennedy, 2000), and the probability of regressions to a skipped but not to a non-skipped word (e.g., Vitu, McConkie, \& Zola, 1998). Concerning the duration component of eye movements, there are mixed findings. Thus, in some studies, increases in word length are associated with increments in both first-fixation time and gaze duration ${ }^{1}$ (Rayner et al., 1996), whereas in others, only gaze duration is related to word length, both in first-pass and second-pass reading (Hyönä \& Olson, 1995). In general, whereas other factors may be important, word length accounts for most of the variability in the forward movements of the eyes, particularly where they move on to and, to a lesser extent, how long the eyes stay on a word.

Lexical frequency is the frequency of a word in written language. There is only limited evidence that word frequency affects the location of eye movements. Thus, compared with low-frequency words, those high in frequency are sometimes more likely to be skipped (less likely to be fixated) and receive fewer fixations or refixations in the first pass (Rayner et al., 1996). However, these effects have not been obtained in other studies investigating probability of fixation (Henderson \& Ferreira, 1993) or number of fixations (Kennison \& Chifton, 1995). Furthermore, other location measures such as launch site (Kennison \& Clifton, 1995) or landing position (Rayner et al., 1996) are not affected by word frequency. In contrast, most measures are generally sensitive to the effects of frequency on the duration of fixations. Thus, either first-fixation duration or gaze duration (normally both) are shorter for high- than for low-frequency words (e.g., Inhoff \& Rayner, 1986; Schilling, Rayner, \& Chumbley, 1998; Rayner \& Duffy, 1986). In addition, second-pass time (Hyönä \& Olson, 1995) and reinspection time (Henderson \& Ferreira, 1993) are also shorter for highthan for low-frequency words.

Contextual constraints have typically been conceptualised as the predictability of a word in a sentence. With regard to the location component of eye movernents, a predictable word is more likely to be skipped than a non-predictable one (Binder, Pollatsek, \& Rayner, 1999; Ehrlich \& Rayner, 1981; O'Regan, 1979; Rayner \& Well, 1996). Likewise, unpredictable words sometimes receive more regressive fixations than predictable words (e.g., Rayner \& Well, 1996), but not others (Morris, 1994). With respect to the duration of fixations, words that are constrained by the context are fixated for less time in first fixation and gaze duration (e.g., Morris, 1994; Binder et al., 1999). It should, however, be noted that findings have sometimes reflected only nonsignificant trends (Altarriba, Kroll, Sholl, \& Rayner, 1996) or lack of effects on first-fixation duration (Rayner \& Well, 1996).

Accordingly, the two main components in readers' behavior, that is, where to fixate and for how long, are influenced by visuat, lexical, and contextual factors. However, each of these factors affects the two eye movement

\footnotetext{
I First-fixation time is the duration of the first fixation on a word or region, independent of the number of fixations on it. Gaze duration is the sum of all fixation durations on a word or region prior to moving to another region, either to the right or to the left.
} 
dimensions differently or independently. Thus, word length is consistently related to the probability and location of fixations (i.e., whether, where, and how often a word is fixated), but its relationship with the duration of fixations is weaker. Lexical frequency is clearly associated with reductions in fixation duration, but its role in the probability and, especially, the location of fixations is weaker or limited to particular conditions. Finally, empirical evidence regarding the effects of contextual predictability is mixed, with both the location and duration of fixations being affected to some extent. This is probably due to the complex nature of contextual sources of intlucnce, for which predictability particularly needs further investigation.

This study attempts to make a contribution to prior research $j$ a number of ways. First, whereas in most ptior studies, normally two of the aforementioned factors (length, frequency, and predictability) have been examined simultaneously, in the present study, all three will be combined, and their specific influence will be estimated. Second, rather than using dichotomous levels for each factor, we will use continuous independent variables, in order to capture their relationship with the eyc movement variables within a wide range of variation. Third, instead of snapshots of single processing stages, we will explore the influence of the factors at issue by means of parafoveal, early, late, and spillover measures across several stages. Lastly, the influence of each factor will be investigated across two kinds of contextual source conditions, that is, global and local priming.

We monitored participants' eye movements while they silently read sentences on a computer scrcen. On-line reading measures for target words embedded in the sentences were collected, along with readers' visual behavior in the regions preceding and following the target word. The target words varied in length, lexical frequency, and predictability from the context sentence, according to a prior norming study (see Materials). Two different context conditions were used (see an example in Table 1). In the global + local priming context condition, the sentence preceding the larget word both induced an inference of an event outcome (represcnted by the target word) with more or less predictability and included several individual words that could prime the target word by associative links. In the local-only (henceforth, local) priming condition, the preceding sentence did not predict any particular event, but jncluded the same potential associative prime words as in the global condition. It should be noted that our specific purpose was not to compare global (mossage-integration) priming versus local (word-to-word) priming effects. Rather, we ajmed to determine the effects of global predictability, along with those of length and frequency. However, because the context sentences used to induce predictability included words that could be lexical or semantically related to the target words, it was necessary to separate the effects of global contextual predictability from those of potential local lexical or semantic association.
Method

Participants

Sixty-four native Spanish-speaking psychology undergraduates at La Laguna University participated for course credit. They had normal uncorrected vision.

\section{Materials}

Ejghty target words and 80 context sentences were used, with each target wort embedded in two versions of each context sentence: a global + local priming condition and a local priming condition (see Table 1 , and further examples in Calvo, Meseguer, \& Carreiras, 2001). In the former condition, the target words represented event outcomes that could result from situations described in the prior sentence, in addition to being semantically associated with some content words in the prior sentence context. In the latter condition, the same target words could be semantically associated with the same context words as in the former condition but did not represent event outcomes that could be predicted by the contex!. Each participant was presented with 40 experimental trials in randon order, interspersed with unrelated filler trials. Half of the experimental trials for each subject belonged to the global + local priming condition; the other haif, to the local priming condition. Trials pertaining 10 cach condition were presented randomly. On each trial, a short passage appeared on a computer screen. This passage was composed of a context sentence and a continuation sentence that contained a pretarget region. a target word, a posttarget region, and a final region. The continuation sentence (including the target word) was identical for both the global + local priming condition and the local priming condition. Each target word (and the corresponding context and continuation sentence) in both priming conditions was read by 16 participants.

Predictability in both context conditions, length, and frequency scores for target words had been previously determined. Predictability scores were obtained from a norming study (cloze task) in which 104 undergraduates were presented with the context sentences up to the target word (not included) and were asked to write down the next word in the sentence, using the first word that came to mind and that was related to the prior context (sce Calvo, Castillo, \& Estévez, 1999). In the global + local priming context condition, prediclability for target words ranged from .00 (no participant produced the word) $10.96(96 \%$ of participants produced it, $M=.43 ; S D=.37$ ). In the local priming context condition, predictability scores ranged from .00 to $.19(M=.04 ; S D=.05)$. The difference between predictability scores for each condition was significant, 1 (79) $=9.22, p<.0001$. The context sentences in both the global + local condition and in the local condition were of 
Table 1

Example of Materials in each of the two Context Conthionts

GILBAL + LOCAL PRIMING CONDITION:

When the *parly was over, there were *hags and *papers all over the *floor. so Susana picked up the *broon. / Susana / swept / the floor / thoroughly./

(Original Spanish version: Al terminar la *fiesta había *bolsas y *papeles por todo el *suelo, así que Susana cogió la *escoba, / Susana I barrio / cl suclo/ completamentel

\section{LOCAL (ONLY) PRIMING CONDITION:}

In order to decorate the "party. Susana hung up the colored *papers with the *broom that was on the *floor. / Susana / swept / the floor I thoroughly.t

(Original Spanish version: Para idornar la *fiesta, Susana colgó *papeles de colores con la *escoba que estaba en el *suelo. / Susana / barrió / el suelo / completamente.f

Note. Target words in italics. Asterisks, slashes, and brackets did not appear in the stimuli. Asterisks indicate the content words shared by both priming contex conditions, to control for word-based priming. Slashes $(/)$ in the continuation sentence separate each of the four regions (i.e., pretarget, target, posttarget, and final).

equivalent length $(M=20.6$ number of words for both contexts; $S D=4.80$ vs. 4.69). Forty-two percent of the same content words were included in the global and the local priming version of each sentence, to control for word-based priming. Target word length ranged from 4 to 11 letters ( $M$ $=6.98 ; S D=2.02$ ). The frequency of the target words, based on Sebastián-Gallés, Martí, Cuetos, and Carteiras' (1996) norms, ranged from 1 to 202 occurrences per million $(M=$ $20 ; S D=25.71$ )

Eye movements were recorded by a Fourward Technologies Dual Purkinje 5.5 Eyetracker, which has a resolution of less than 10 min of arc. The eyetracker was interfaced with an IBM compatible PC that controlled stimulus display and data storage. The position of the eye was sampled every millisecond, and the computer stored data on the duration and location of each fixation for later analysis. The computer was also interfaced with a superVGA visual display unit on which the stimulus passages were presented. The display was $60 \mathrm{~cm}$ from the participant's cyc. Participants viewed the screen with their heads positioned on a deep chin rest and forehead rest, with a strap around the head, to minimize movements. Each passage was presented in three lines up to 80 characters per line. The regions of interest (pretarget, target, and posttarget) were located in the third line, which began with the last context word and ended with the final region of the continuation sentence.

\section{Procedure}

Before the experiment started, participants were informed that the study was about reading comprehension. They were told to read silenly at their normal rate and that they would periodically be required to answer questions about the passages. The participant sat in front of the eyeltacker and calibration was performed. Six practice passages were presented before the experimental trials. When readers finished each passage, they pressed a key and the computer either displayed a (yes/no response) recognition question on half of the trials, or proceeded to the next passage. Readers responded by pressing one of two buttons. This procedure was used to ensure that the participants were comprehending the sentences.

\section{Measures}

Five groups of eyc movement measures were examined for the target (global, early, and late), pretarget (parafoveal), and postarget (spillover) regions.

First, global measures: (a) total fixation time, that is, total time spent fixating the target word; and (b) total number of fixations received by this word.

Second, parafoveal measures obtained from the pretarget region (to examine whether properties of the target word, while presented in the parafovea, influenced the processing of the pretarget word undergoing concurrent foveal inspection): (c) duration of the last fixation on the pretarget region ( $n-1$ duration) before first entering the target region; (d) launch site or the last location of the eyes before first landing on the target word $(n-1$ launch site, in number of characters from the beginning of the target word).

Third, early (foveal) measures in the target region: (e) probability of fixation on the target word (n) when initially encountered; (D) landing position of first fixation (in number of characters from the beginning of $n$ ); $(g)$ firstfixation duration on $n$, independent of the number of fixations; (h) first-pass reading lime or gaze duration, which is the sum of all fixation durations on $n$ prior to moving to another region; (i) number of fixations received during first-pass reading; and (j) launch site on the larget word when first leaving this region forward to another region (n launch site). 
Fourth, late (foveal) processing measures: (k) probability of regressions from the target word to prior regions, that is, backward eye movements that begin on $n$ in the first pass, and leave the currently fixated region to the left $(n \rightarrow n-1$, $n-2$, etc. regressions); (1) fixation time in rereading regions prior to the target word before leaving this region forward ( $n \rightarrow n-1, n-2$, etc. rereading time); (m) probability of inward regressions to the target word after having left this region forward; $(n)$ second-pass fixation time on the target word, which is the time spent fixating $n$ after the reader has fixated at least once away from it forward; (o) probability of regressions from the posttarget region $(n+1$ regressions); and $(p)$ number of fixations on the target word in secondpass reading.

Fifth, spillover measures: (q) length of forward saccade from the target word to the posttarget region in the first pass; and (r) duration of the first fixation on the postarget region when first leaving the target word on the right $(n+1$ fixation duration). Kennedy (2000) has made a relevant distinction between parafoveal-on-foveal effects (which would be detected with our parafoveal measures) and foveal-on-parafoveal effects (which would be detected with our spillover measures).

Results

\section{Descriptive Statistics}

Preliminary analyses involved overall characteristics of the data set. Table 2 presents the means for cye movement measures in each context condition. In general, global priming facilitated reading, in comparison with local priming, as revealed by a reduction in total reading time per target word in the global + local priming condition. ${ }^{2}$ This reduction probably comes from facilitation of late processes involving text integration, rather than from facilitation of carly lexical access processes. Thus, the four measures in which global priming was facilitatory involved late (and spillover) processes. This was revealed by less second-pass fixation time for the target word, fewer second-pass fixations, fewer regressions from the posttarget region, and shorter first-fixation duration after having left the target word in a forward direction, in the global + local priming condition in comparison with the local priming condition.

\section{Relative Contributions of Length, Frequency, and Predictability in the Global + Local Priming Condition}

The most interesting analyses involved multiple linear regression, with word length, frequency, and predictability of the target words as simultaneous predictors, and each cye movement measure as a dependent variable. ${ }^{3}$ The natural logarithm of word frequency was used, instead of the absolute mean frequency scores (see justifications in Reichle, Pollatsek, Fisher, \& Rayner, 1998, p. 136). The following statistics are particularly useful to interpret the multiple regression analyses (see Tabachnick \& Fidell, 1989): (a) the squared multiple correlation, or $R^{2}$, which is the proportion of the variance in the dependent variable that is accounted for by the best linear combination of all predictors, that is, combined contribution (the sum of joint and unique contributions); (b) the beta coefficient, or $\beta$, expressing the standardized slope or estimate of the change in the dependent variable with each unit of change in the predictor; and (c) the squated semipartial correlation, or

2 It should be noted that we did not aim to compare both conditions. An appropriate approach for that purpose would have required selecting those items in which there was high predictability ftom the global + local priming context (i.e., with a predictability score above .50), as well as their matching counterparts in the local priming condition. Our main point regarding the possible comparison of these conditions is that global predictability affects late rather than early processes. This is demonstrated by the fact that reductions in predictability (Iocal priming condition) affected late processing measures, but not the other measures. Nevertheless, it could be argued that the facilitatory effect of the global priming condition might be due not only to the lact that mean predictability scores were higher in this condition than in the local condition, but also because the range of variability was higher in the former than in the latter condition, thus increasing the statistical power of predictability as a predictor variable in the regression analysis.

3 We computed regression analyses on item (i.e., words) variability, thus averaging means across subjects. In contrast to this approach, Lorch and Myers (1990) have proposed an aitemative regression analysis that takes subject variability into account, which is normally considered an optimal procedure. Lorch and Myers point out that, in the analysis based on item means, the estimates of the percentage of variance accounted for by the predictor variables are inflated (although estimates of the population regression coefficients are unbiased). However, we have not followed this alternative approach for two reasons. The first is concened with the fact that both the predictor and the dependent variables were characteristics of the items, with the predictor scores being the same for all subjects (i.e., the length, frequency, and predictability of a given word were identical for all subjects reading it). Accordingly, though ihere was subject variatility for the dependent variables (i.e, eye-fixations in reading), there was no variability for the predictors. The second reason is concerned with the fact that the standard regression analysis based on subject variatbility "does not provide values of $R^{2}$ or semipartial $\left(\omega^{2}\right)$ correlation coefficients" (Lorch \& Myers, 1990, p. 153). These regression statistics are essential tools for the aim of the present study, i.e.. to quantify the relative contribution of each predictor. This is why we have chosen the more traditional itetn analysis approach. 
Table 2

Means and Standard Deviations for Each Eye movement Measure in the Global + Local Priming Conditon and in the Local (only) Prining Condition, and Significant Differences Between Conditions.

\begin{tabular}{|c|c|c|c|c|c|}
\hline \multirow[b]{3}{*}{ Eye movement Measures } & \multicolumn{4}{|c|}{ Priming context } & \multirow[b]{3}{*}{$179)$} \\
\hline & \multicolumn{2}{|c|}{ Global + Local } & \multicolumn{2}{|c|}{ Local (only) } & \\
\hline & $M$ & $S D$ & $M$ & $S D$ & \\
\hline \multicolumn{6}{|l|}{ GLOBAL MEASURES } \\
\hline Total Fixation Time $n$ & 475 & 149 & 500 & 163 & $1.95 \%$ \\
\hline Total Number Fixations $n$ & 1.84 & .66 & 1.88 & .62 & 0.69 \\
\hline \multicolumn{6}{|l|}{ PARAFOVEAL MEASURES } \\
\hline n-1 Fixation Duration & 251 & 26 & 250 & 24 & 0.29 \\
\hline n-1 Launch Site & 6.56 & 2.21 & 6.57 & 1.61 & 0.01 \\
\hline \multicolumn{6}{|l|}{ EARLY PROCESSING MESAURES } \\
\hline Probability of Fixation $n$ & .91 & .07 & .93 & .09 & 1.19 \\
\hline Landing Position $n$ & 3.06 & 0.62 & 2.95 & 0.73 & 1.79 \\
\hline I $^{\text {st-Fixation Duration } n}$ & 266 & 21 & 265 & 19 & 0.42 \\
\hline Gaze Duration n & 351 & 82 & 362 & 91 & 1.39 \\
\hline No. of $1^{\text {st }}$-Pass Fixations $n$ & 1.30 & 0.39 & 1.27 & 0.36 & 1.20 \\
\hline Launch Site $n$ & 4.93 & 1.11 & 4.97 & 1.27 & 0.28 \\
\hline \multicolumn{6}{|l|}{ LATE PROCESSING MEASURES } \\
\hline$n \rightarrow n-1,2 \ldots$ Probability Regressions & .07 & .09 & .08 & .09 & 1.27 \\
\hline$n \rightarrow n-1,2 \ldots$. Re-reading Time & 45 & 46 & 44 & 42 & 0.06 \\
\hline Inward Regressions to $n$ & .20 & .14 & .20 & .13 & 0.37 \\
\hline$n 2^{\text {nd-Pass Fixation Time }}$ & 130 & 101 & 159 & 103 & $2.14 *$ \\
\hline Probability Regressions from $n+1$ & .10 & .09 & .14 & .11 & $2.70 * *$ \\
\hline No. of $2^{\text {nd }}$-Pass Fixations $n$ & .52 & .38 & .61 & .38 & $2.07 *$ \\
\hline \multicolumn{6}{|l|}{ SPILLOVER MEASURES } \\
\hline$n \rightarrow n+1$ Saccade Length & 7.69 & 1.12 & 7.53 & 1.11 & 1.29 \\
\hline$n+11^{\text {st }}$-Fixation Duration & 239 & 25 & 247 & 22 & $2.18 \%$ \\
\hline
\end{tabular}

$s r^{2}$, which indicates the unique contribution of each predictor to $R^{2}$ after the contribution of the other predictors is taken out. Pairwise correlations between the three predictors were statistically non-significant (predictability and length: $r=-.04$; predictability and frequency: $r=-.02$; length and frequency: $r=.12$ ), which avoids collinearity problems.

The combined predictors accounted for a statisticaliy significant portion of variance (i.e., $R^{2}$ : see Table 3 ): (a) in both global measures of eye movements, such as total reading time, $55 \%$ of variance explained, $F(1,76)=31.97$, $p<.0001$, and number of fixations on the target word, $64 \%$, $F(1,76)=45.85, p<.0001$; (b) in all early processing measures, such as probability of first-pass fixation on the target word, $32 \%, F(1,76)=11.39, p<.0001$, landing position, $49 \%, F(1,76)=23.93, p<.0001$, first-fixation duration, $23 \% ; F(1,76)=7.60, p<.001$, gaze duration,
$61 \%, F(1,76)=39.52, p<.0001$, number of first-pass fixations, $72 \%, F(1,76)=65.48, p<.0001$, and launch site from the target word, $38 \%, F(1,76)=15.55, p<.0001$; (c) in most late processing measures, including probability of regressions to the target word, $32 \%, F(1,76)=12.03, p<$ .0001 , second-pass reading time on the target word, $40 \%$, $F(1,76)=16.44, p<.0001$, probability of regressions from the target word, $31 \%, F(1,76)=11.20, p<.0001$, and number of second-pass fixations on the target word, $40 \%$, $F(1,76)=16.85, p<.0001$, except for regressions from the target word to prior regions, and rereading time of these regions; and (d) in both spillover measures, such as forward saccade length from the target word, $28 \%, F(1,76)=9.84$, $p<.000 \mathrm{I}$, and first-fixation duration after leaving the target word, $18 \%, F(1,76)=5.52, p<.01$. In contrast, neither of the parafoveal (-on-fovcal) measures seemed to be affected by the predictors. 
Table 3

Antown of Total Variance $\left(R^{2}\right)$ in each Dependent Variable Acconted for by the Best Linear Combination of all Predictors (Joint and Unique Contributions), and Unique Variance (sr ${ }^{2}$ ) Explained by each Predictor (Word Length, Lexical Frequency. and Contextual Predictability), in the Global + Local Priming Condition

\begin{tabular}{|c|c|c|c|c|}
\hline \multirow[b]{2}{*}{ Dependent Variables } & \multirow[b]{2}{*}{$R^{2}$} & \multicolumn{3}{|c|}{ Predictors } \\
\hline & & $\begin{array}{l}\text { Word Length } \\
\qquad s r^{2}\end{array}$ & $\begin{array}{l}\text { Lexical Frequency } \\
\qquad s r^{2}\end{array}$ & $\begin{array}{c}\text { Contextual predictability } \\
\qquad s r^{2}\end{array}$ \\
\hline \multicolumn{5}{|l|}{ GLOBAL MEASURES } \\
\hline Total Fixation Time $n$ & $.55^{* * *}$ & $.31^{* * * *}$ & $.05^{* *}$ & $.11^{* * *}$ \\
\hline Total Number Fixations $n$ & $.64^{* * * *}$ & $.46^{* * *}$ & .02 & $.09^{* * *}$ \\
\hline \multicolumn{5}{|l|}{ PARAFOVEAL MEASURES } \\
\hline n-1 Fixation Duration & .03 & .01 & .01 & .01 \\
\hline n-1 Launch Site & .05 & .02 & .02 & .00 \\
\hline \multicolumn{5}{|l|}{ EARLY PROCESSING MESAURES } \\
\hline Probability of Fixation $n$ & $.32^{* * *}$ & $.28^{* * * *}$ & .00 & .01 \\
\hline Landing Position $n$ & $.49^{* * *}$ & $.45^{* * * *}$ & .00 & .01 \\
\hline $1^{\text {st_Fixation Duration } n}$ & $.23^{* * *}$ & .03 & $.19^{* * * *}$ & .03 \\
\hline Gaze Duration $n$ & $.61^{* * *}$ & $.41^{* * * *}$ & $.10^{* *}$ & .01 \\
\hline No. of $1^{\text {st-Pass Fixations } n}$ & $.72^{* * *}$ & $.61^{* * *}$ & .03 & .01 \\
\hline Launch Site $n$ & $.38^{* * *}$ & $.37^{* \% * *}$ & .01 & .00 \\
\hline \multicolumn{5}{|l|}{ LATE PROCESSING MEASURES } \\
\hline$n \rightarrow n-1,2 \ldots$ Probability Regressions & .05 & .02 & .00 & .00 \\
\hline$n \rightarrow n-1,2 \ldots$ Re-reading Time & .05 & .04 & .00 & .00 \\
\hline Inward Regressions to $n$ & $.32^{* * * *}$ & .01 & $.0 \mathrm{I}$ & $.29^{* * *}$ \\
\hline$n 2^{\text {nd }}$-Pass Fixation Time & $.40^{* * *}$ & $.11^{* *}$ & .02 & $.23^{* * *}$ \\
\hline Probability Regressions from $n+1$ & $.31^{* * *}$ & .01 & .02 & $.29^{* * *}$ \\
\hline No. of $2^{\text {nd }}$-Pass Fixations $n$ & $.40^{* * *}$ & $.14^{* * *}$ & .00 & $.22^{* * *}$ \\
\hline \multicolumn{5}{|l|}{ SPILLOVER MEASURES } \\
\hline$n \rightarrow n+1$ Saccade Length & $.28^{* * *}$ & $.28^{* * *}$ & .00 & .00 \\
\hline$n+11^{\text {st-Fixation Duration }}$ & $.18^{* *}$ & .04 & $.05^{*}$ & $.09^{* *}$ \\
\hline
\end{tabular}

$*_{p}<.05 .{ }^{* *} p<.01 . * * * p<.001$.

Regarding the specific or unique contributions of each predictor (i.e., $s r^{2}$ ), Table 3 shows that word length was the only significant predictor of probability of fixation, $28 \%$ of variance, $\beta=.54, p<.001$, landing position, $45 \%, \beta=.68$, $p<.001$, number of fixations in the first pass on target words, $61 \%, \beta=.80, p<.001$, launch site from target words, $38 \%, \beta=.63, p<.001$, and length of saccade to positarget regions, $28 \%, \beta=.52, p<.001$. Length was also the best predictor of total reading time, $31 \%, \beta=.57, p<.001$, total number of fixations, $46 \%, \beta=.69, p<.001$, and gaze duration on target words, $41 \%, \beta=.65, p<.001$. In all cases, increases in length were followed by increases in each eye movement measure. In contrast, length did not make any contribution to parafoveal (-on-foveal) measures, firstfixation duration on the target word or on $n+1$, or to various late processing measures.

Lexical frequency was the only significant predictor with a unique contribution to first-fixation duration on target word, $19 \%, \beta=-.43, p<.001$. Though to a Iesser extent than the other predictors, frequency also affected several measures related to fixation duration, such as total time on target word, $5 \%, \beta=-.24, p<.01$, gaze duration, $10 \%$, $\beta=.30, p<.001$, and $n+1$ fixation duration, $5 \%, \beta=-.24$, $p<.05$. In all cases, increases in frequency resulted in reductions in the eyc movement measures. In contrast, word frequency did not account for any significant variations in fixation location measures of any kind or in fixation durations in late processing.

Contextual predictability was the only signilicant predictor of probability of regressions to target words, $29 \%, \beta=-.53$, $p<.001$, and from postuarget regions, $29 \%, \beta=-.54, p<$ .001 , and the best predictor of second-pass reading time, $23 \%, \beta=-.48, p<.001$, number of fixations in the secondpass, $20 \%, \beta=-.47, p<.001$, and duration of the lirst fixation on $n+1,9 \%, \beta=-.30, p<.01$. Predictability also accounted for a significant portion of variance in both global 
measures of eye movements, such as total time, $11 \%, \beta=$ $-33, p<.00 \mathrm{~L}$, and number of fixations, $9 \%, \beta=-.30, p<$ .001. In all cases, the more predictable a target word was, the less likely it was to be fixated and the shorter the fixation time. In contrast, predictability was not significantly related to any parafoveal (-on-foveal) or to early processing measures.

Effects of Length, Frequency, and Predictability in the Local (only) Priming Condition

Table 4 shows the contributions of the predictors to the dependent variables when the target word could be semantically primed by individual words in the prior context but not by global inferential predictability. The combined predictors accounted for a significant portion of variance in both global eye movement measures $(47$ to $56 \%$, all $p \mathrm{~s}<$
.0001 ), all early processing measures ( 18 to $67 \%$, all $p \mathrm{~s}<$ .001 ), most late processing measures (from 14 to $23 \%$, all $p s<.001$ ), and spillover measures ( 8 to 27\%, $p<.05$ ); in contrast, no parafoveal (-on-foveal) measure was affected.

Regarding the specific contributions, first, predictability lost most of its power, relative to the global + local priming condition. Thus, predictability no longer accounted for variations in global measures, spillover measures, and most late processing measures. It maintained some influence on two late measures, such as probability, $5 \%, \beta=-.24, p<$ .05 , and duration, $4 \%, \beta=-.20, p=.056$, of fixations in the second pass of the target word. However, the amount of this influence was lower in the local priming condition than in the global + local condition. This was revealed by statistical contrasts between mean pcrcentages of explained variance (i.e., $5 \%$ vs. $29 \%$, and $4 \%$ vs. $23 \%$; both, $p<.001$ ).

Table 4

Amount of Total Variance $\left(R^{2}\right)$ in each Dependent Variable Accounted for by the Best Linear Conbination of all Predictors (Joint and Unique Contributions), and Unique Variance $\left(s r^{2}\right)$ Explained by each Predictor (Word Length, Lexical Frequency and Contextual Predictability), in the Local (only) Priming Condition. The Comparison with the Global + Local Priming Condition (Table 3) is Indicated by $G$ and NG (see Note below).

\begin{tabular}{|c|c|c|c|c|}
\hline \multirow[b]{2}{*}{ Dependent Variables } & \multirow[b]{2}{*}{$R^{2}$} & \multicolumn{3}{|c|}{ Ptedictors } \\
\hline & & $\begin{array}{l}\text { Word Length } \\
\qquad s r^{2}\end{array}$ & $\begin{array}{l}\text { Lexical Frequency } \\
\qquad s r^{2}\end{array}$ & $\begin{array}{c}\text { Contextual predictability } \\
\qquad s r^{2}\end{array}$ \\
\hline \multicolumn{5}{|l|}{ GLOBAL MEASURES } \\
\hline Total Fixation Time $n$ & $.47^{* * *} \mathrm{G}$ & $.37^{* * *} \mathrm{G}$ & $.04 \mathrm{G}$ & $.01 \mathrm{G}$ \\
\hline Total Number Fixations $n$ & $.56^{* * *} \mathrm{G}$ & $.46^{* \cdots * k} \mathrm{G}$ & .02 & $.00 \mathrm{G}$ \\
\hline \multicolumn{5}{|l|}{ PARAFOVEAL MEASURES } \\
\hline$n-1$ Fixation Duration & .05 & .03 & .02 & .00 \\
\hline$n-1$ Launch Site & .03 & .00 & .00 & .02 \\
\hline \multicolumn{5}{|l|}{ EARLY PROCESSING MESAURES } \\
\hline Probability of Fixation $n$ & $.27^{* * *} \mathrm{G}$ & $.24^{* * * *} \mathrm{G}$ & .00 & .00 \\
\hline Landing Position $n$ & $.48^{* * *} \mathrm{G}$ & $.43^{* * *} \mathrm{G}$ & .00 & .00 \\
\hline $1^{\text {st-Fixation Duration } n}$ & $.18^{* * *} \mathrm{G}$ & .01 & $.17^{* * *} \mathrm{G}$ & .00 \\
\hline Gaze Duration $n$ & $.59^{* * *+} \mathrm{G}$ & $.40^{* * * *} \mathrm{G}$ & $.06^{*} \mathrm{G}$ & .01 \\
\hline No. of $1^{\text {st.Pass Fixations } n}$ & $.67^{* * * *} \mathrm{G}$ & $.50^{* * *} \mathrm{G}$ & .03 & .01 \\
\hline Launch Site $n$ & $.44^{* * *} \mathrm{G}$ & $.38^{* * *} \mathrm{G}$ & .00 & .01 \\
\hline \multicolumn{5}{|l|}{ LATE PROCESSING MEASURES } \\
\hline$n \rightarrow n-1,2 \ldots$ Probability Regressions & .04 & .00 & .00 & .03 \\
\hline${ }_{n} \rightarrow n-\mathbf{1}, 2 \ldots$. Re-reading Time & .03 & .00 & .02 & .00 \\
\hline Inward Regressions to $n$ & $.14^{* *} \mathrm{G}$ & .01 & $.06^{*} \mathrm{NG}$ & $.05^{*} \mathrm{G}$ \\
\hline$n 2^{\text {nd }}-$ Pass Fixation rime & $.22^{* * *} \mathrm{G}$ & $.10^{* * *} \mathrm{G}$ & $.05^{*} \mathrm{NG}$ & $.04^{\#} \mathrm{G}$ \\
\hline Probability Regressions from $n+1$ & $14^{* *} \mathrm{G}$ & .00 & $.12^{* * *} \mathrm{NG}$ & $.00 \mathrm{G}$ \\
\hline No. of $2^{\text {nd }}$-Pass Fixations $n$ & $.23^{* * *} \mathrm{G}$ & $.19^{* * *} \mathrm{G}$ & .00 & $.03 \mathrm{G}$ \\
\hline \multicolumn{5}{|l|}{ SPILLOVER MEASURES } \\
\hline$n \rightarrow n+1$ Saccade Length & $.27^{* * *} \mathrm{G}$ & $.23^{* * *} \mathrm{G}$ & .00 & .00 \\
\hline$n+11^{\text {st. Fixation Duration }}$ & $.08^{*} \mathrm{G}$ & .01 & $.06^{*} \mathrm{G}$ & $.00 \mathrm{G}$ \\
\hline
\end{tabular}

$\# p=.06 . * p<.05 . * k p<.01 . * * p<.001$.

Note: $\mathrm{G}=$ Significant effects in the Global + Local priming condition. NG = Nonsignificant effects in the Global + Local priming condition. 
Second, word length maintained almost the same influence in both context conditions, and therefore was not affected by the absence of global predictability. Third, in contrast, the significant reduction of influence for predictability had some remarkable repercussions on the contribution of word frequency. This occurred specifically whenever predictability lost its predominant role, that is, in the late processing measures. Thus, in the local priming condition, frequency significantly accounted for variations in the probability, $6 \%, \beta=-.24, p<.05$, and duration, $5 \%$, $\beta=-.22, p<.05$, of reinspections in second-pass reading of the target word and in the probability of regressions from the posttarget region, $12 \%, \beta=-36, p<.01$, an effect that frequency did not have in the global + local priming condition. In all other cases, the pattern of influence for frequency remained essentially unchanged in both conditions.

\section{Discussion}

We shall discuss the relevance of the reported findings to the three main issues addressed by the present study: (a) the relative contribution of word length, frequency, and predictability to eye movements in reading; (b) the lime course of this influence across processing stages, particularly in relation to the when and where mechanisms assumed to govern eyc movements; and (c) the sources of the contextual predictability effects.

The Contribution of Word Length, Frequency, and Predictability Across Processing Stages and Mechanisms:

Taking the effects of each independent variable separately, most of our findings are consistent with those reported in prior research, except for predictability (see review in the introduction; below we address the inconsistencies regarding predictability). Nevertheless, our results make a contribution in that they reveal the relative influence of word length, frequency, and predictability, after the other factors are partialled out. The fact that there was no collinearity between the predictors facilitates the estimation of the unique influence of each predictor. Word length had a greater independent influence than the other predictors. The variance explained by length was $25 \%$ on average, across the eye movement measures that were significantly predicted by any combination of the factors. The average variations explained by frequency and by prediclability were $4 \%$ and $10 \%$, respectively. Nevertheless, this overall variance accounted for by each factor has low informative value in qualitative terms.

More important is the relative influence across processing stages and mechanisms, that is, the moment at which each factor becomes active in influencing eyc movements (and to what extent), and the question of which main component of fixations, that is, duration and location. is affected (and how much). Regarding word length, it becomes active early in processing a word. Probably because word-length information is acquired parafoveally (see Rayner, 1998), length affects the probability of first fixation on a word and the landing position. Likewise, our results are consistent with those indicating that length continues to be a useful predictor of gaze duration even when the effects of frequency and predictability are partialled out (Rayner \& Fischer, 1996), though these effects are not detected in first-fixation duration (see also Hyönä \& Olson, 1995). Accordingly, the early effects of word length seem more strongly related to where (and how likely) to lixate than to when to move the eyes (or how long to fixale). Apart from these early effects. word length continues to have later clfects on both components of eye movement behavior. This was revealed by an influence on the duration and number of fixations in the second pass (see also Hyoua \& Olson, 1995). It must, however, be noted that, in our results, the important contribution of word length in the early processing measures decreased in the late measures, with predictability laking the leading role.

Word frequency begins to influence processing at an early stage, mainly involving lexical access to the form and meaning of words (sce Reichle et al., 1998). This is demonstrated by an effect on first-fixation duration and gaze duration. Moreover, the fact that the effects on second-pass reading time are more difficult to obtain suggests that the influence of frequency is mostly confined to early processing stages and does not extend to later stages (see also Hyönä \& Olson, 1995). Only one finding in our data, duration of $n+1$ fixation, suggests that frequency might have a late effect (see also Kennison \& Clifton, 1995). But even this result could be reinterpreted as carly facilitation in processing the next word. Thus, high frequency for the $n$ target word would save time in lexical (foveal) processing of this word, which could be used for parafoveal processing of the next word, $n+1$, therefore producing a preview benefit while still fixating word $n$ (see Rejchle et al., 1998, pp. 137-138). Accordingly, frequency has mainly (if not exclusively) a specific contribution at an early processing stage. Furthermore, frequency affects the duration component (i.e., how long to fixate) of eye movements, but not the location component at this stage.

Word predictability intervenes only in late processing stages. The lack of effect of predictability on the early measures in our study deserves special attention, as it is not consistent with findings from a considerable number of prior studies (Altarriba et al., 1996; Lavigne, Vitu, \& D'Ydewalle, 2000; Morris, 1994; Rayner \& Well, 1996). An explanation for this discrepancy, involving the contrast between local and global contextual priming sources, will be addicssed below. For the moment, we can highlight the late effects found in the present study. That predictability can affect late processing stages has already been demonstrated by prior research, as reflected in regressive 
fixations to unpredictable target words (e.g., Rayner \& Well, 1996). What is new in this study is that, firstly, predictability is clearly the best predictor of variations in late processing measures; and, secondly, predictability affects both where and how long to fixate during the second pass. Furthermore, according to the distinction made by Hyönä and Pollatsek (2000), our data revealed that predictability affected the how likely dimension of the where component, but not the within-word location dimension (e.g., saccade length from $n$ to $n+1$ ).

\section{The Source of Contextual Predictability Effects}

In contrast to the relatively consistent effects of word length and frequency, the findings regarding contextual predictability show some discrepancies between the present study and prior research. Some studies have shown that contextual predictability facilitates early processes, whereas in our study, only late measures were affected. Early effects have been reported for either of the following measures: probability of skipping (e.g., Altarriba et al., 1996), landing position (Lavigne et al., 2000; though Rayner, Binder, Ashby, \& Pollatsek, 2001, found no effects of predictability on where the eyes landed when the predictable word was not skipped), first-fixation duration (e.g., Morris, 1994), or gaze duration (e.g., Balota, Pollatsek, \& Rayner, 1985).

This discrepancy may be explained by a conceptualization that assumes the existence of different context sources that can act at different processing levels (see Hess, Foss, \& Carroll, 1995; Morris, 1994). One mechanism involves semantic or lexical word-based priming, by means of which, for example, reading the word wedding in a preceding context may activate the Iexical entry corresponding to the target word cake (Balota et al., 1985). This would result in a more efficient lexical access to cake when the corresponding word is read, thus affecting early processing stages. This mechanism was probably responsible for the early effects found in most of the aforementioned studies. Thus, Morris (1994) used context sentences such as The barber trimmed the mustache this moming, where mustache was the target word, of which barber and trimmed are close lexical associates. In Lavigne et al. (2000), target words such as trousers were embedded in a sentence context such as The belt held up the trousers of the old man, where belt probably has a strong priming effect on trousers. This also applies to the materials used by Altarriba et al. (1996), with context sentences such as $H e$ needed to put a stanp on the letter before he malled it, where stamp is highly related to the target word letter.

The olher mechanism involves the formation of an integrated representation of the content of the context sentence, or an elaborative inference based on the combination of contextual information. Such a representation would probably be active at a later postaccess stage (after the access to each of the individual context words and theit corresponding lexical priming has occurred) and would serve to integrate the context with the upcoming (target) words. This integration would take time to develop or to refine and complete. Such a mechanism was probably involved in the processing of our sentences and would explain the late, instead of early, effects that we found. This explanation can also be applied to one study (Hyönä, 1993) that found late, but not early, effects on eye movement measures: The context sentences were probably thematically, rather than lexically, related to the target words, as they "could be easily incorporated in a summarizing statement of the text passage" (Hyönä, 1993, p. 195). Garrod and Terras (2000) have provided further support for our conceptualization, as they found delayed contextual effects (i.e., in second-pass time on the target word, and in regressions from a posttarget region), while lexical effects appeared earlier (i.e., in firstpass reading of the target word and of the posttarget region).

Furthermore, the comparison of our two priming conditions provides relevant information on this issue. First, and most important, the contribution of contextual predictability almost totally derives from a global source, rather than from local semantic association: The strong influence of predictability in the global + local priming condition on global, late, and spillover measures significantly decreased or disappeared in the local priming condition. This allows us to conclude that most of our contextual effects were due to inferential rather than to associative priming. The source of influence was presumably the generation of a high-order elaborative inference from the context as a whole (see Calvo et al,, 2001). This inference would represent a likely event outcome following the situation described in the context. This type of inference has been shown to take time to get activated (e.g., Calvo, 2000; Calvo et al., 1999). Presumably, it involves postaccess messagelevel processes whose main function is to facilitate the integration of the lexical entry (e.g, the target word) that has been accessed into the higher-order representation of the context sentence. This is why the major contribution of contextual predictability was detected in late eye movement measures.

In summary, word length, frequency, and predictability account for a significant variance in eye movements in reading (about $60 \%$ in the global measures, with noticeable variations across processing stages). After the influence of the other factors is partialled out, the influence of word length extends to most (if not all) processing stages, and involves measures of both how long to fixate (except on first-fixation durations) and where to fixate (both regarding how likely/often a word is fixated and the within word location). Word frequency affects how long a word is fixated (but not where to fixate) in an early processing stage. The contribution of contextual predictability is restricted to late processing stages, with influence on how long to fixate a word and on one aspect of the where to look component (i.e., how likely and often a word is fixated), but not the other (i.e., the within-word location of fixation). The source 
of influence of predictability is attributable to global contextual priming (i.c., gencration of an integrated inference) rather than to associative word-based priming. The contribution of word length is independent of the presence or absence of contextual predictability, whereas frequency seems to adopt a compensatory role when predictability loses its influence. In general, these findings support cognitive models of eye movement control assuming the existence of two different mechanisms. a when and a where mechanism, that are relatively independently influenced by cognicive variables such as word frequency and predictability, whereas word length has a generalized influence (sce Brysbaert \& Vitu, 1998; Rayner, 1998).

\section{References}

Altarriba, J., Kroll, J.F., Sholl, A., \& Rayner, K. (1996). The influence of lexical and conceptual constraints on reading mixed-language sentences: Evidence from eye fixations and naming times. Memory and Cognirion, 24, 477-492.

Balota, D.A., Pollatsek. A., \& Rayner, K. (1985). The interaction of contextual constraints and parafoveal visual information in reading. Cognitive Psychology: $17,364-390$.

Binder, K.S. Pollatsek, A., \& Rayner, K. (1999). Extraction of information to the left of the fixated word in reading. Journal of Experimental Psychology: Hamam Perception and Performance, 25, 1162-1172.

Brysbacrt, M., \& Vitu, F. (1998). Word skipping: Implications for theories of cye movement control in reading. In $G$. Lndenwood (Ed.), Eye gudance in reading and scene perception (pp. 125147). Oxford, UK: Elsevier.

Calvo, M.G. (2000). The time course of predictive inferences depends on contextual constraints. Language and Cognitive Processes. 15, 293-319.

Calvo, M.G., Castillo, M.D., \& Estevez, A. (1999), On-ine predictive inferences: Processing time during vs. after the priming context. Memory ant Cognition, 27, 834-843.

Calvo, M.G., Meseguer, E., \& Carreiras, M. (2001). Interences about predictable events: Eye movements during reading. Psychological Research, 65, 158-169.

Ehrlich, S.F., \& Rayner, K. (1981). Contextual effects on word perception and eye movements during reading. Journal of Verbal Leaming and Verbal Behavior, 20, 641-655.

Garrod, S., \& Terras, M. (2000). The contribution of lexical and situational knowledge 10 resolving discourse roles: Bonding and resolution. Jounal of Monory and Language, 42, 526-544.

Henderson. J.M., \& Ferreira, F. (1993). Eye movement control during reading: Fixation measures reflect foveal but not parafoveal processing difficulty, Cunadian Joumal of Experintental Psychology, 47, 201-22].

Hess. D.J., Foss, D.J., \& Carroll, P. (1995). Effects of global and local context on lexical processing during language comprehersion. Jounal of Experimental Psychology: General, $124,62-82$.
Hyönï. 3. (1993). Effects of thematic and lexical priming on readers eye movements. Scondinarian Joumal of Psychology, 34. $293-304$

Hyönt, J., \& Olson, R.K. (1995). Eye fixation patterns among dyslexic and normal readers: Effects of word length and word frequency. Joumal of Experinental Psychology: Leaming. Memory, and Cognition, 21, 1430-1440.

Hyönü. J.. \& Pollatsek, A. (2000). Processing of Finnish compound words in reading. In A. Kennedy. R. Radach, D. Heller, \& J. Pynte (Eds.), Reading as a perceptual process (pp. 65-87). Oxford. UK: Elsevier.

Inluoff, A.W., \& Rayner, K. (1986). Parafoveal word processing during eye fixations in reading: Effects of word frequency. Pereption and Pswhoplysics, 40, 431-439.

Kennedy. A. (2000). Paraloveal processing in word recognition. The Quaterly Jounal of Expermental Pswchotogy. 53A, 429-455.

Kennison, S.M. \& Ctifton, C. (1995). Determinants of parafoveal preview benefit in high and low working memory capacity readers: Implications for cye movement control. Jownal of Experimental Psichology: Leaming, Menory, and Cogntition, $21,68-81$.

Lavigne, F. Vitu, F. \& d'Ydewalle. G. (2000). The inlluence of scmantic context on initial landing sites in words. Acta Psychologica, 104, 191-214.

Lorch, R.F. \& Myers, J.L. (1990). Regression analyses of repeated measures data in cognitjve research. Journal of Experimental Psychology: Leaming, Menory, and Cognition, 16, 149-157.

McConkie, G.W., Kerr, P.W.. Reddix, M.D. \& Zola, D. (1988). Eye movement control during reading: $\mathbf{l}$. The location of initial eye fixations on words. Vision Resworch, 27, 227-240.

Morris, R.K. (1994). Lexical and message-level sentence context effects on tixation times in reading. Jounal of Experimental Psychology: Leaming, Memory and Cognition, 20, 92-103.

O'Regan. J.K. (1979). Eye guidance in reading: Evidence for the linguistic control hypothesis. Pereption and Prohophysics, $25,501-509$.

Rayner, K. (1979). Eye guidance in reading: Fixation locations withirt words. Papteprion, 8, 21-30.

Rayner. K. (1998). Eye movements in reading and information processing: 20 years of research. Psychological Bulletin. 124 , $372-422$.

Rayner, K., Binder, K.S., Ashby, J., \& Pollatsek, A. (2001). Eye movement control in reading: Word predictability has lirte influence on initial landing positions in words. Vision Researth. $41,943-954$

Rayner. K., \& Duffy. S.A. (1986). Lexical complexily and tixation times in reading: Effects of word frequency, verb complexity, and lexical ambiguity. Memory and Cognition, 14, 191-201.

Rayner. K., \& Fischer, M.H. (1996). Mindless reading revisited: Eye movements during reading and scanning are different. Perception and Psychophysics. 58, 734-747.

Rayner. K.. McConkie. G.W. (1976). What guides a reader's eye movements. Vision Research, 16.829-837.

Rayncr, K., Sereno. S.C., \& Raney, G.E. (1996). Eye movement control in reading: A comparison of two types of models 
Joumal of Experimental Psychology: Leaming, Menory, and Cognition. 22, $1188-1200$.

Rayner, K., \& Well, A.D. (1996). Effects of contextual constraint on eye movements in reading: A further examination. Psychonomic Bulletin and Review, 3, 504-509.

Reichle. E.D., Pollatsek, A., Fisher, D.L.. \& Rayner, K. (1998). Toward a model of cye movement control in reading. Psychological Revien: 105. 125-157.

Sebastián-Gallés, N., Martí, M.A., Cuetos, F., \& Carteiras, M. (1996). LEXESP: Una base de datos infomatizada del español. Barcclona, Spain: University of Barcelona.

Schilling, H.E., Rayner. K.. \& Chumbley. J.I. (1998). Comparing naming, lexical decision, and eye fixation times: Word frequency effects and individual differences. Menory and Cognition, 26, 1270-1281.

Tabachnick, B.G., \& Fidell, L.S. (1989). Using multivariate statistics. New York: Harper.

Vitu. F., McConkie. G.W. \& Zola, D. (1998). About regressive saccades and their relation to word identification. In $G$. Underwood (Ed.). Eye guidance in reading and scene perception (pp. 101-124). Oxford, UK: Elsevier.

Received November 16, 2001 Revision received March 6, 2002 Accepted March 11, 2002 



\section{ORDER FORM}

\section{THE SPANISH JOURNAL OF PSYCHOLOGY}

Please enter my annual subscription (2002) at the following rate (singles issues half price):
$\square$ Individual Rate
G. Institutional Rate

Europe

$\square$ Other Countries
20 euros

25 euros $\square$ Europe

$\square$ Other Countries
30 euros

40 euros

\section{Method of Payment}

\section{Bank money order payable to:}

The Spanish Journal of Psychology

Banco Central Hispano

Somosaguas, 28223 - Madrid (Spain)

To account No.: $0049 / 2197 / 52 / 2414025461$

\section{Credit Card}

$\begin{array}{ll}\square \text { Visa } & \square \text { American Express } \\ \square \text { Mastercard } & \square \text { Diner's Club }\end{array}$

Card No:

Expiry Date:

Signature:

Date:

Country:

Send this order form to: Servicio de Publicaciones

Universidad Complutense

Isaac Peral s/n

E-28040 Madrid (Spain) 


$$
\cdots
$$

